\title{
Exfoliation and europium(III)-functionalization of $\alpha$-titanium phosphate via propylamine intercalation: From multilayer assemblies to single nanosheets ${ }^{\S}$
}

\author{
Jorge García-Glez ${ }^{\mathrm{a}} \cdot$ Camino Trobajo $^{\mathrm{a}} \cdot$ Alaa Adawy $^{\mathrm{b}} \cdot$ Zakariae Amghouz $^{\mathrm{c}}$ \\ ${ }^{a}$ Department of Organic and Inorganic Chemistry, and ${ }^{b}$ Scientific and Technical Services, \\ University of Oviedo-CINN, 33006 Oviedo, Spain \\ ${ }^{c}$ Department of Materials Science and Metallurgical Engineering, University of Oviedo, 33203 \\ Gijón, Spain \\ Zakariae Amghouz amghouzzakariae@uniovi.es \\ $\S$ Dedicated to Prof. Abraham Clearfield, a luminary in the field of materials science for more \\ than 60 years, on his 90th birthday.
}

\begin{abstract}
Layered $\alpha$-titanium phosphate intercalated with propylamine, $\mathrm{Ti}\left(\mathrm{HPO}_{4}\right)_{2} \cdot 2 \mathrm{C}_{3} \mathrm{H}_{7} \mathrm{NH}_{2} \cdot \mathrm{H}_{2} \mathrm{O}(\alpha-$ TiPPr), has been synthesized by solid-vapour reaction and then exfoliated via a single-stage approach based on overnight stirring in aqueous medium. The obtained nanosheets were then functionalized using solid-liquid reaction with europium(III) nitrate aqueous solutions. The obtained materials were characterized by powder X-ray diffraction (PXRD), $\mathrm{N}_{2}$ adsorptiondesorption isotherms at $77 \mathrm{~K}$, scanning electron microscopy (SEM), transmission electron microscopy (TEM, SAED, STEM-EDX), atomic force microscopy (AFM) and photoluminescence spectroscopy (PL). The europium(III) sorption takes place via two distinct pathways, the first is the previously reported $\mathrm{C}_{3} \mathrm{H}_{7} \mathrm{NH}_{3}{ }^{+} /\left[\mathrm{Eu}\left(\mathrm{H}_{2} \mathrm{O}\right)_{6}\right]^{3+}$ ion-exchange process into the titanium-phosphate interlayer space of the multilayered $\alpha$-TiPPr. The second pathway is the self-assembly of single-sheets which is provoked by electrostatic interactions
\end{abstract}


between the negatively charged titanium-phosphate sheets and the Eu(III)-aqueous cations, leading to the formation of layered ultra-nanoparticles.

Keywords Titanium phosphate $\cdot$ Propylamine $\cdot$ Exfoliation $\cdot$ Europium $\cdot$ Luminescence

\section{Introduction}

Although metal salts of phosphoric acid have been known for over a century, research on layered metal phosphates only began in the end of 1950's after some of these salts have been utilized as cation exchangers in radioactive waste streams (Kraus et al. 1956). In the beginning, tetravalent metal phosphates were only available as amorphous gels owing to their low solubility. In 1964, Clearfield and Stynes (Clearfield et al. 1964) prepared the first crystalline compound, $\alpha-\mathrm{Zr}\left(\mathrm{HPO}_{4}\right)_{2} \cdot \mathrm{H}_{2} \mathrm{O}(\alpha-\mathrm{ZrP})$, which made their layered structure (Troup et al. 1977) and chemical reactivity (Kullberg et al. 1981) clearly understood. Later, the $\gamma$ layered compound, $\gamma-\mathrm{Zr}\left(\mathrm{PO}_{4}\right)\left(\mathrm{H}_{2} \mathrm{PO}_{4}\right) \cdot 2 \mathrm{H}_{2} \mathrm{O}(\gamma-\mathrm{ZrP})$, was also reported by Clearfield et al. (Clearfield et al. 1968). Not only can titanium phosphate be prepared as a gel or in intermediate stages of crystallinity, but also in several crystalline forms including $\alpha$ - and $\gamma$ TiP (Salvadó el al. 1996; García-Granda el al. 2010). These layered tetravalent metal phosphates, with strong bonds in two dimensions and weak bonds in the third one, usually undergo two kinds of chemical reactions. The first one is the intercalation reactions that occur with the retention of the two-dimensional bonding, where the interlayer spacing could be expanded enough to absorb the guest molecules (Menéndez et al. 1993; Espina et al. 1998; Espina el al. 1998). In this case, the material remains crystalline or semi-crystalline, because of the absorptive interactions between the guest and the sheets of the host (Espina el al. 200; Mafra et al. 2005; Mafra el al. 2008). The other type of reaction is the exfoliation, which can be considered an extreme case of intercalation. In this case, the forces between the sheets are 
weakly attractive or even repulsive, resulting in easily separable (nano)sheets by the effect of solvent molecules (Brunet 2010).

Two-dimensional (2D) nanosheets possessing atomic or molecular thickness and infinite planar dimensions are the thinnest known functional nanomaterials. These 2D nanosheets, derived from the layered parent materials via exfoliation processes, have recently gained increasing attention because of their outstanding functionalities and ability to serve as building blocks (Osada et al. 2012; Wassei el al. 2013). Exfoliated nanosheets have been realized by implementing graphite oxide (Parvez el al. 2014; Xia el al. 2013), transition metal dichalcogenides (e.g. $\mathrm{MoS}_{2}$, and $\mathrm{MoSe}_{2}$ ) (Coleman el al. 2011; O'Neill et al. 2012), layered double hydroxides (LDHs, e.g. $\mathrm{M}(\mathrm{II})-\mathrm{Al}-\mathrm{CO}_{3}$ where $\mathrm{M}=\mathrm{Zn}, \mathrm{Ni}, \mathrm{Co}, \mathrm{Fe}$ ) (Liu et al, 2007; Liu el al. 2007), and metal oxides $\left(\mathrm{Ca}_{2} \mathrm{Nb}_{3} \mathrm{O}_{10} 0^{-}, \mathrm{Ti}_{4} \mathrm{O}_{9}{ }^{2-}, \mathrm{MnO}_{2}{ }^{-0.45}\right)($ Oshima el al. 2015; Jeffery el al. 2016; Wang el al. 2004). In principle, these materials undergo exfoliation in solvents to form colloidal dispersions of single layer nanosheets. Under specific conditions, they can form dimers and higher aggregates of individual sheets. Interestingly, these lamellar colloids can be re-stacked to make the parent solid or its intercalation compounds, and this feature has prompted their use as precursors, for nanocomposites and layered self-assembled hybrids.

Nowadays, exfoliation of layered tetravalent metal phosphate (e.g. $\alpha-\mathrm{ZrP}, \gamma-\mathrm{ZrP}$ and $\alpha$-TiP) has also received considerable attention (Alberti el al. 2000; Takei el al. 2006; Tanaka el al. 2010), especially their ability to reassemble with functional guest molecules (Sun el al. 2007; Kumar el al. 2000; Chaudhari el al. 2005; Kim el al. 1997). This implies the possibility of combining $\alpha$-TiP nanosheets and cationic species, via adsorption processes, to further explore the plausible novel functionalities of these layered tetravalent metal phosphates. We have recently reported that when $\alpha$-TiP is used as $\mathrm{Eu}^{3+}$-sorbent in aqueous media, the material's surface is responsible only for the adsorption (Ortiz-Oliveros el al. 2014; GarcíaGlez el al. 2016), while the interlayer space is solely accessible to the europium species when 
the basal spacing is already expanded and an amine-intercalation product, $\mathrm{Ti}\left(\mathrm{HPO}_{4}\right)_{2} \cdot 2 \mathrm{C}_{3} \mathrm{H}_{7} \mathrm{NH}_{2} \cdot \mathrm{H}_{2} \mathrm{O}(\alpha-\mathrm{TiPPr})$, is used as a starting material (García-Glez el al. 2016). Under these operating conditions, a complex process takes place that includes partial hydrolysis of the titanium phosphate with the precipitation of crystalline europium phosphates and titanium dioxide gels together with the transformation of $\alpha$-TiPPr to $\alpha-$ $\left[\mathrm{Eu}\left(\mathrm{H}_{2} \mathrm{O}\right)_{6}\right]_{2 / 3} \operatorname{Ti}\left(\mathrm{PO}_{4}\right)_{2} \cdot\left[\left(\mathrm{H}_{2} \mathrm{O}\right)_{6}\right]_{1 / 3}$ via an ion-exchange mechanism. In the present work, the exfoliation of $\alpha$-TiP intercalated with propylamine ( $\alpha$-TiPPr) and its $\mathrm{Eu}(\mathrm{III})$-functionalization via sorption processes is proposed as an efficient procedure for the synthesis of luminescent layered ultra-nanoparticles.

\section{Materials and methods}

\subsection{Experimental procedures}

n-propylamine (98\%) and europium(III) nitrate pentahydrate (99.9\%) were purchased from Sigma-Aldrich and used as received. The starting material, $\alpha$-TiPPr, was obtained by placing $\alpha$-TiP in an atmosphere saturated with propylamine vapor for 6 days at room temperature (Menéndez et al. 1990). In a bath, four equal samples, each constituted $0.3 \mathrm{~g}$ of $\alpha$-TiPPr were equilibrated by adding $6 \mathrm{~mL}$ of $10^{-4} \mathrm{M}$ europium nitrate solution $(\mathrm{T}=25.0 \pm$ $0.1{ }^{\circ} \mathrm{C}, \mathrm{t}=72 \mathrm{~h}$, solution/solid ratio $=20 \mathrm{~mL} / \mathrm{g}$ ) to provoke the material's exfoliation as previously described (García-Glez el al. 2016). By in situ addition of different amounts of MilliQ water and $0.25 \mathrm{M}$ europium(III) nitrate solution $(\mathrm{pH} 3.94)$ to a total volume of 8.4 $\mathrm{mL}$, four samples Eu_x ( $\boldsymbol{x}$ indicates the total volume added, in $\mathrm{mL}$, of europium nitrate solution) were prepared. Eu_o was taken as the reference sample that was prepared by adding a total volume of $2.4 \mathrm{~mL}$ of MilliQ water in three successive portions of $0.8 \mathrm{~mL}$ separated by $1 \mathrm{~h}$ of stirring. The mixture was then stirred for $24 \mathrm{~h}$ before being centrifuged. In a similar 
procedure, Eu_0.8 was obtained by adding two portions of $0.8 \mathrm{~mL}$ MilliQ water followed by $0.8 \mathrm{~mL}$ of europium nitrate solution. For Eu_1.6, one portion of $0.8 \mathrm{~mL}$ MilliQ water followed by two portions of $0.8 \mathrm{~mL}$ europium nitrate solution were added. Finally, Eu_2.4 has been obtained after adding three successive portions $(0.8 \mathrm{~mL}$ each $)$ of europium nitrate solution. The elemental analysis results on carbon are summarized in Table S1 (see Electronic Supporting Information, ESI).

\subsection{Characterization procedures}

The powder X-ray diffraction (PXRD) patterns were recorded on X'pert Panalytical diffractometer with $\mathrm{Cu}-\mathrm{K} \alpha$ radiation $(\lambda=1.5418 \AA)$. The samples were gently ground in an agate mortar in order to minimize the preferred orientation. A Mettler-Toledo equipment $\left(\mathrm{TGA} / \mathrm{SDTA} 851^{\mathrm{e}}\right)$ were used for the thermal analyses in oxygen dynamic atmosphere (50 $\mathrm{mL} / \mathrm{min}$ ) at a heating rate of $10{ }^{\circ} \mathrm{C} / \mathrm{min}$. In TG test, a Pfeiffer Vacuum ThermoStar ${ }^{\mathrm{TM}}$ GSD301T mass spectrometer was used to determine the evacuated vapours. Micrographs and X-ray microanalysis (SEM/EDX) were recorded with a JEOL JSM-6100 electron microscope operating at $20 \mathrm{kV}$ coupled with an X-Max SDD $80 \mathrm{~mm}^{2}$ energy dispersive X-ray spectroscopy (EDS) detector from Oxford instruments. The TEM studies were performed on a JEOL JEM-2100F field emission transmission electron microscope operated at an accelerating voltage of $200 \mathrm{kV}$ and equipped with an ultra-high resolution pole-piece that provided a point-resolution better than $0.19 \mathrm{~nm}$. Fine powder of the sample was dispersed in ethanol, sonified and sprayed on a carbon coated copper grid, and then allowed to air-dry. The Atomic force microscopy (AFM) images were obtained with a NanotecTM AFM. The Photoluminescence studies at RT were obtained using a standard spectrofluorometer Edinburgh Instruments FLSP920, having a 450W Xe lamp as the excitation source. The 
sample was placed between two quartz plates placed at $45^{\circ}$ from the incident beam and the detector. $\mathrm{N}_{2}$ adsorption-desorption isotherms were recorded at $77 \mathrm{~K}$ on a Micromeritics ASAP 2020 instrument. The degassing of the samples was performed at $100{ }^{\circ} \mathrm{C}$ for $17 \mathrm{~h}$.

\section{Results and discussion}

The powder XRD patterns of Eu_x samples are shown in Fig. 1. The structural ordering in the direction perpendicular to the plane of the sheet is still observable in the case of the exfoliated $\alpha$-TiPPr (Eu_0), with the first characteristic peak at $2 \theta=5.5^{\circ}$ and $d$-spacing of $16.0 \AA$ which correspond to the interlayered distance in the starting structure of the layered $\alpha$-TiPPr. However, we observed that for $\mathbf{E u} \_\mathbf{0 . 8}$ to $\mathbf{E u} \_2.4$ the structural ordering decreased substantially with the increase in the concentration of europium in the contact solutions.

The nitrogen adsorption-desorption isotherms at $77 \mathrm{~K}$ of the samples $\alpha$-TiP (a), $\alpha$ TiPPr (b) and Eu_2.4 (c) are shown in Fig 2. All the adsorption isotherms are Type II according to the BDDT classification (Thommes et al. 2015), which indicates that the adsorption process takes place in a mono-multilayer with negligible porosity. The application of BET method over the adsorption branches gives the BET surface area of $6.5 \mathrm{~m}^{2} \mathrm{~g}^{-1}$ for $\alpha$ TiP, $9.9 \mathrm{~m}^{2} \mathrm{~g}^{-1}$ for $\alpha$-TiPPr $38 \mathrm{~m}^{2} \mathrm{~g}^{-1}$ for Eu_0.8, $53 \mathbf{~ m}^{\mathbf{2}} \mathrm{g}^{-1}$ for Eu_1.6 and $110 \mathrm{~m}^{2} \mathrm{~g}^{-1}$ for Eu_2.4. The high values observed for the surface area in case of Eu_0.8, Eu_1.6 and Eu_2.4 samples are attributed to the exfoliation process of $\alpha$-TiPPr, as well as the increase of $\mathrm{Eu}(\mathrm{III})$ content.

The morphology of Eu_x samples were characterized by SEM and the results are presented in Fig. 3. The pristine $\alpha$-TiPPr exhibits hexagonal shaped plates (Fig. S1, ESI), indicative of high crystallinity. After the exfoliation of $\alpha$-TiPPr $\left(\mathbf{E u} \_\mathbf{0}\right)$, the shaped hexagonal plates disappeared, and the nanosheets are tightly stacked and slightly wrinkled (Fig. 3a). 
After europium species was adsorbed nto $\alpha$-TiPPr nanosheets, aggregate-like nanoparticles along with roughly layered morphologies could be observed (Fig. 3b-d). However, no obvious different observations can be seen between $\mathbf{E u} \_\mathbf{0 . 8}$ to $\mathbf{E u} \_\mathbf{2 . 4}$, and the sizes of these aggregates are still too small to be visualized and estimated directly from the SEM images (Fig. 3b-d). Overall, these results are highly consistent with the PXRD analysis (Fig. 1).

As mentioned above, the pristine $\alpha$-TiPPr was exfoliated via overnight stirring to produce $\alpha$-TiPPr sheets $\left(\mathbf{E u} \_\mathbf{0}\right)$. TEM analyses were performed for the as-prepared $\alpha$-TiPPr sheets (Eu_0) and for all the solids Eu_0.8, Eu_1.6 and Eu_2.4 treated with Eu(III), and the observations are shown in Fig. 4. Figs. 4a-c show a general view of Eu_0, clearly illustrating that the crystalline $\alpha$-TiPPr could be fully exfoliated into individual nanosheets by the process implemented here. From the TEM data of Eu_0.8, Eu_1.6 and Eu_2.4 presented in Fig. 4d-1, it is obvious that there are two type of easily distinguishable morphologies: (1) the stacked $\alpha$ TiPPr sheets, which are probably uniformly decorated and/or intercalated by Eu(III) species; (2) the aggregated nanosheets, which tend to pile up into larger particles at increasing Eu(III) concentrations.

The chemical composition of these morphologies was inspected by EDX analysis in the Bright-Field Scanning Transmission Electron Microscopy (BF-STEM) mode (including line-scan and mapping analyses); the results are illustrated in Fig. 5 and Figs. S2-S6 in ESI. These results reveal that both $\alpha$-TiPPr sheets and the nano-aggregates contain $\mathrm{Eu}(\mathrm{III})$ species, and that the $\mathrm{Eu}(\mathrm{III})$ content increases in the stacked $\alpha$-TiPPr sheets as the starting $\mathrm{Eu}(\mathrm{III})$ concentration increases, indicating that the immobilization/sorption of $\mathrm{Eu}(\mathrm{III})$ species is successful. The EDX elemental mapping of carbon (Fig. 5 and Figs. S2, S4, S6 in ESI) shows that these large stacked $\alpha$-TiPPr sheets is still intercalated with the propylamine. In addition, their propylamine content decreases as the starting $\mathrm{Eu}(\mathrm{III})$ concentration increases, in agreement with the results of elemental analysis on carbon, as shown in Table S1. These two 
observations suggest that the $\mathrm{Eu}(\mathrm{III})$ retention/absorption is a consequence of an ionexchange process into the interlayer space of the layered titanium phosphate, that involves propylammonium cations and europium(III) species. The second observed morphology, nano-aggregates, are most probably formed by the self-assembly of single $\alpha$-TiPPr nanosheets that takes place after they adsorbe Eu(III) species on their both sides, because of the electrostatic interaction between these negatively charged $\alpha$-TiPPr sheets and Eu(III) species. Therefore, we can conclude that the mechanism of Eu retention may be initially caused by the degree of exfoliation of the $\alpha$-TiPPr hexagonal plates.

To confirm the above hypothesis about the exfoliation degree of the $\alpha$-TiPPr hexagonal plates, an AFM study was performed for Eu_o solid, and the results are illustrated in the Fig. 6 and Fig. S7 in ESI. The results reveal that the exfoliation leads to variations in both size ( $c a .100 \mathrm{~nm}$ to $600 \mathrm{~nm}$ - agreeing with TEM results) and thickness (ca. $8 \AA$ up to 50 $\mathrm{nm})$ of the sheets. As per AFM data, the measured thickness for the particles with the size between $c a$. 100-170 nm, $c a .200 \mathrm{~nm}$ to $300 \mathrm{~nm}$ and larger than $350 \mathrm{~nm}$ were ranging from ca. 0.8 to $12 \mathrm{~nm}, c a .10-20 \mathrm{~nm}$, and $c a .30 \mathrm{~nm}$ to $50 \mathrm{~nm}$, respectively.

To investigate the photoluminescence properties of $\mathbf{E u} \_\boldsymbol{x}$ samples, the emission spectra were obtained under $\lambda_{\mathrm{ex}}=394 \mathrm{~nm}$ (direct intra $4 \mathrm{f}^{6}$ excitation, ${ }^{7} \mathrm{~F}_{0} \rightarrow{ }^{5} \mathrm{~L}_{6}$ ), as shown in Fig. 7. The emission spectrum of Eu_0, as expected, does not show any transition line due to absence of the $\mathrm{Eu}^{3+}$ sorption. Whereas, Eu_0.8, Eu_1.6 and Eu_2.4 spectra show the typical emission transitions of $\mathrm{Eu}^{3+}$ (Atuchin el al. 2014; Shi el al. 2014; Ji el al. 2015; Amghouz el al. 2011; Amghouz el al. 2012; Abdelbaky el al. 2016), which are attributed to ${ }^{5} \mathrm{D}_{0} \rightarrow{ }^{7} \mathrm{~F}_{\mathrm{J}}(\mathrm{J}=$ 1-4) transitions at $591 \mathrm{~nm}\left({ }^{5} \mathrm{D}_{0} \rightarrow{ }^{7} \mathrm{~F}_{1}\right), 616 \mathrm{~nm}\left({ }^{5} \mathrm{D}_{0} \rightarrow{ }^{7} \mathrm{~F}_{2}\right), 650 \mathrm{~nm}\left({ }^{5} \mathrm{D}_{0} \rightarrow{ }^{7} \mathrm{~F}_{3}\right)$, and 689 and $697 \mathrm{~nm}\left({ }^{5} \mathrm{D}_{0} \rightarrow{ }^{7} \mathrm{~F}_{4}\right)$, with the most intense peak corresponding to ${ }^{5} \mathrm{D}_{0} \rightarrow{ }^{7} \mathrm{~F}_{4}$ transition. The emission spectra show an increase in the relative intensities of ${ }^{5} \mathrm{D}_{0} \rightarrow{ }^{7} \mathrm{~F}_{0-4}$ transition peaks as 
the starting $\mathrm{Eu}(\mathrm{III})$ concentration increases. This indicates that the Eu-content increases in solid phase accordingly.

It is well known that the intensity of the hypersensitive ${ }^{5} \mathrm{D}_{0} \rightarrow{ }^{7} \mathrm{~F}_{2}$ transition is strongly dependent on the local symmetry of the $\mathrm{Eu}^{3+}$ cation and the nature of the ligands surrounding it. Whereas, the intensity of the ${ }^{5} \mathrm{D}_{0} \rightarrow{ }^{7} \mathrm{~F}_{4}$ transition is influenced not only by the symmetry factors, but also by the nature of the host matrix (chemical composition, electronegativity, the radius of the rare earth elements and of other trivalent cations) (Ferreira el al. 2006). It has been observed that the luminescence spectra of the Eu-containing compounds with $\mathrm{Eu}^{3+}$ local site symmetry $\mathrm{D}_{4 \mathrm{~d}}$ are often dominated by the ${ }^{5} \mathrm{D}_{0} \rightarrow{ }^{7} \mathrm{~F}_{4}$ transition. In the absence of a center of inversion, the ${ }^{5} \mathrm{D}_{0} \rightarrow{ }^{7} \mathrm{~F}_{4}$ transition intensity is, in most cases, as intense as the ${ }^{5} \mathrm{D}_{0} \rightarrow{ }^{7} \mathrm{~F}_{2}$ one (Binnemans 2015). Since the $\mathrm{Eu}^{3+}$ cation is expected to be hydrated $\left(\left[\mathrm{Eu}\left(\mathrm{H}_{2} \mathrm{O}\right) \mathrm{n}\right]^{3+}\right.$ species where $n=6-9)$, the abnormally dominant emission at ca. $700 \mathrm{~nm}\left({ }^{5} \mathrm{D}_{0} \rightarrow{ }^{7} \mathrm{~F}_{4}\right)$ with intensity comparable to ${ }^{5} \mathrm{D}_{0} \rightarrow{ }^{7} \mathrm{~F}_{2}$ transition at $616 \mathrm{~nm}$ could be attributed to the presence of eightcoordinate species $\left[\mathrm{Eu}\left(\mathrm{H}_{2} \mathrm{O}\right)_{8}\right]^{3+}$ with a square antiprism geometry ( $\mathrm{D}_{4 \mathrm{~d}}$ local environment) rather than $\left[\mathrm{Eu}\left(\mathrm{H}_{2} \mathrm{O}\right)_{6}\right]^{3+}$ species $\left(\mathrm{D}_{4 \mathrm{~h}}\right.$ local environment).

The luminescence decay curves for Eu_1.6 and Eu_2.4 samples are shown in Fig. S8 in ESI, which are monitored within the ${ }^{5} \mathrm{D}_{0} \rightarrow{ }^{7} \mathrm{~F}_{4}(697 \mathrm{~nm})$ transition under direct intra $4 \mathrm{f}^{6}$ excitation (394 nm, $\left.{ }^{7} \mathrm{~F}_{0} \rightarrow{ }^{5} \mathrm{~L}_{6}\right)$. As can be seen, the ${ }^{5} \mathrm{D}_{0} \rightarrow{ }^{7} \mathrm{~F}_{4}$ transition decays exponentially, and the data can be best fitted using a biexponential function as $I(t)=A_{l} \exp \left(-\mathrm{t} / \tau_{1}\right)+A_{2} \exp (-$ $\left.\mathrm{t} / \tau_{2}\right)$, where $I(t)$ is the luminescence intensity, $t$ is the time after excitation, $A_{1}$ and $A_{2}$ are constants, and $\tau_{1}$ and $\tau_{2}$ are the decay times for the exponential components. As shown in Table 1 , both values of $\tau_{1}$ and $\tau_{2}$ components slightly increase with an increase of Eu(III)content in solid phase. $\tau_{1}$ increases from 0.16 to $0.26 \mathrm{~ms}$ and $\tau_{2}$ increases from 0.51 to 0.65 ms. This reveals that the luminescence decay can be associated with two different ways of radiative decay. In this case, $\mathrm{Eu}(\mathrm{III})$ cations adsorbed on the surface of the $\alpha$-TiPPr 
nanosheets could be the main contributor of the fast component as the surface is rich with disordered $\mathrm{Eu}(\mathrm{III})$ cations due to the surface defects compared to the inner core (intercalated/absorbed) $\mathrm{Eu}(\mathrm{III})$ species that could be the source of the slow component (Ninjbadgar el al. 2009).

\section{Conclusions}

We have shown that $\alpha$-TiPPr nanosheets could be easily obtained by exfoliating the hexagonal-shaped $\alpha$-TiPPr particles via a simple approach based on overnight stirring in aqueous medium. The europium(III)-functionalization of the obtained $\alpha$-TiPPr nanosheets, by a solid-liquid reaction in aqueous solutions of europium(III) nitrate, leads to two distinguishable morphologies: The large stacked sheets and aggregated nanosheets. This can be explained by the fact that the Eu(III)-sorption takes place by two different pathways: $i$ ) ion-exchange/absorption process involving propylammonium cations and $\mathrm{Eu}(\mathrm{III})$ species and, ii) adsorption of $\mathrm{Eu}(\mathrm{III})$ species on the surface of single $\alpha$-TiPPr nanosheets, and these two pathways are in turn attributed to the degree of exfoliation of $\alpha$-TiPPr. We believe that the methodology presented here can serve as a simple and efficient route for the synthesis of luminescent layered ultra-nanoparticles of tetravalent metal phosphates. In addition, it implies the possibility of combining other tetravalent metal phosphate nanosheets and cationic species to further explore the plausible novel functionalities.

\section{Acknowledgments}

Financial support from Spanish Ministerio de Economía y Competitividad (MAT201340950-R and MAT2016-78155-C2-1-R) and Gobierno del Principado de Asturias (GRUPIN14-060), and FEDER funding are acknowledged. 


\section{Appendix A. Supplementary data}

Supplementary data associated with this article can be found online at http://

\section{References}

Abdelbaky, M.S.M., Amghouz, Z., García-Granda, S., García, J.R.: Synthesis, Structures and Luminescence Properties of Metal-Organic Frameworks Based on Lithium- Lanthanide and Terephthalate. Polymers 8, 86 (2016)

Alberti, G., Cavalaglio, S., Dionigi, C., Marmottini, F.: Formation of aqueous colloidal dispersions of exfoliated $\gamma$-zirconium phosphate by intercalation of short alkylamines, Langmuir 16, 7663-7668 (2000)

Amghouz, Z., García-Granda, S., García, J.R., Clearfield, A., Valiente, R.: Organic-inorganic hybrids assembled from lanthanide and 1, 4-phenylenebis (phosphonate). Cryst. Growth Des. 11, 5289-5297 (2011)

Amghouz, Z., García-Granda, S., García, J.R., Ferreira, R.A.S., Mafra, L., Carlos, L. D., Rocha, J.: Series of metal organic frameworks assembled from Ln (III), Na (I), and Chiral flexible-achiral rigid dicarboxylates exhibiting tunable UV-vis-IR light emission. Inorg. Chem. 51, 1703-1716 (2012)

Atuchin, V.V., Aleksandrovsky, A.S., Chimitova, O.D., Gavrilova, T.A., Krylov, A.S., Molokeev, M.S., Oreshonkov, A.S., Bazarov, B.G., Bazarova, J.G.: Synthesis and Spectroscopic Properties of Monoclinic $\alpha-E u 2\left(\mathrm{MoO}_{4}\right) 3$. J. Phys. Chem. C 118, 15404$15411(2014)$

Binnemans, K.: Interpretation of europium(III) spectra. Coord. Chem. Reviews 295, 1-45 (2015)

Brunet, E.: Usual molecules in unusual environments displaying unusual properties. Aust. J. Chem. 63, 1679-1685 (2010)

Chaudhari, A., Kumar, C.V.: Intercalation of proteins into $\alpha$-zirconium phosphonates: Tuning the binding affinities with phosphonate functions. Micropor. Mesopor. Mater. 77, 175187 (2005)

Clearfield, A., Blessing, R.H., Stynes, J.A.: New crystalline phases of zirconium phosphate possessing ion-exchange properties. J. Inorg. Nucl. Chem. 14, 2249-2258 (1968)

Clearfield, A., Stynes, J.A.: The preparation of crystalline zirconium phosphate and some observations on its ion exchange behavior. J. Inorg. Nucl. Chem. 26. 117-129 (1964)

Coleman, J.N., Lotya, M., O'Neill, A., Bergin, S.D., King, P.J., Khan, U., Young, K., Gaucher, A., De, S., Smith, R.J., Shvets, I.V., Arora, S.K., Stanton, G., Kim, H.Y., Lee, K., Kim, G.T., Duesberg, G.S., Hallam, T., Boland, J.J., Wang, J.J., Donegan, J.F., Grunlan, J.C., Moriarty, G., Shmeliov, A., Nicholls, R.J., Perkins, J.M., Grieveson, E.M., Theuwissen, K., McComb, D.W., Nellist, P.D., Nicolosi, V.: Two-dimensional nanosheets produced by liquid exfoliation of layered materials, Science 331, 568-571 (2011) 
Espina, A., García, J.R., Guil, J.M., Jaimez, E., Parra, J.B., Rodríguez, J.: Calorimetric study of amine adsorption on $\alpha$ - and $\gamma$-titanium phosphate. J. Phys. Chem. B 102, 1713-1716 (1998)

Espina, A., Jaimez, E., Khainakov, S.A., Trobajo, C., García, J.R., Rodríguez, J.: Synthesis of new $n$-alkyldiamines intercalation compounds into $\alpha$-titanium phosphate. Process selectivity and structural and morphological characterization. Chem. Mater. 10, 2490-2496 (1998)

Espina, A., Trobajo, C., Khainakov, S.A., García, J.R., Bortun, A.I.: Intercalation of $n$ alkylamines into layered materials: A method for the recognition of isomorphism in semicrystalline compounds. J. Chem. Soc., Dalton Trans. 753-757 (2001)

Ferreira, R.A.S., Nobre, S.S., Granadeiro, C.M., Nogueira, H.I.S., Carlos, L.D., Malta, O.L.: A theoretical interpretation of the abnormal ${ }^{5} \mathrm{D}_{0-}{ }^{7} \mathrm{~F}^{4}$ intensity based on the $\mathrm{Eu}^{3+}$ local coordination in theNa9[EuW $\left.{ }_{10} \mathrm{O}_{36}\right] \cdot 14 \mathrm{H}_{2} \mathrm{O}$ polyoxometalate. J. Lumin. 121, 561-567 (2006)

García-Glez, J., Trobajo, C., Khainakov, S.A., Amghouz, Z.: $\alpha$-Titanium phosphate intercalated with propylamine: An alternative pathway for efficient europium(III) uptake into layered tetravalent metal phosphates. Arab. J. Chem. 10, 885-894 (2016)

García-Granda, S., Khainakov, S.A., Espina, A., García, J.R., Castro, G.R., Rocha, J., Mafra. L.: Revisiting the thermal decomposition of layered $\gamma$-titanium phosphate and structural elucidation of its intermediate phases. Inorg. Chem. 49, 2630-2638 (2010)

Jeffery, A.A., Pradeep, A., Rajamathi, M.: Preparation of titanate nanosheets and nanoribbons by exfoliation of amine intercalated titanates. Phys. Chem. Chem. Phys. 18, 1260412609 (2016)

Ji, H., Huang, Z., Xia, Z., Molokeev, M.S., Jiang, X., Lin, Z., Atuchin, V.V.: Comparative investigations of the crystal structure and photoluminescence property of eulytite-type $\mathrm{Ba} 3 \mathrm{Eu}\left(\mathrm{PO}_{4}\right)_{3}$ and $\mathrm{Sr}_{3} \mathrm{Eu}\left(\mathrm{PO}_{4}\right)_{3}$. Dalton Trans. 44, 7679-7686 (2015)

Kim, H.N., Keller, S.W., Mallouk, T.E., Schmitt, J., Decher, G.: Characterization of zirconium phosphate/polycation thin films grown by sequential adsorption reactions. Chem. Mater. 9, 1414-1421 (1997)

Kraus, K.A., Phillips, H.O.: Adsorption on inorganic materials. 1. Cation exchange properties of zirconium phosphate. J. Am. Chem. Soc. 78, 694-694 (1956)

Kullberg, L., Clearfield, A.: Mechanism of ion-exchange in zirconium phosphates. 32. Thermodynamics of alkali-metal ion-exchange on crystalline $\alpha$-ZrP. J. Phys. Chem. 85, 1585-1589 (1981)

Kumar, C.V., Chaudhari, A.: Proteins immobilized at the galleries of layered $\alpha$-zirconium phosphate: Structure and activity studies. J. Am. Chem. Soc. 122, 830-837 (2000)

Liu, Z.P., Ma, R.Z., Ebina, Y., Iyi, N., Takada, K., Sasaki, T.: General synthesis and delamination of highly crystalline transition-metal-bearing layered double hydroxides. Langmuir 23, 861-867 (2007)

Liu, Z.P., Ma, R.Z., Osada, M., Iyi, N., Ebina, Y., Takada, K., Sasaki, T.: Synthesis, anion exchange, and delamination of Co-Al layered double hydroxide: Assembly of the exfoliated nanosheet/polyanion composite films and magneto-optical studies. J. Am. Chem. Soc. 128, 4872-4880 (2007)

Mafra, L., Paz, F.A.A., Rocha, J., Espina, A., Khainakov, S.A., García, J.R., Fernández, C.: Structural characterization of layered $\gamma$-titanium phosphate $\left(\mathrm{C}_{6} \mathrm{H}_{13} \mathrm{NH}_{3}\right)\left[\mathrm{Ti}\left(\mathrm{HPO}_{4}\right)\left(\mathrm{PO}_{4}\right)\right]$ $\cdot \mathrm{H}_{2} \mathrm{O}$. Chem. Mater. 17, 6287-6294 (2005)

Mafra, L., Rocha, J., Fernández, C., Castro, G.R., García-Granda, S., Espina, A., Khainakov, S.A., García, J.R.: Characterization of layered $\gamma$-titanium phosphate 
$\left(\mathrm{C}_{2} \mathrm{H}_{5} \mathrm{NH}_{3}\right)\left[\mathrm{Ti}\left(\mathrm{H}_{1.5} \mathrm{PO}_{4}\right)\left(\mathrm{PO}_{4}\right)\right]_{2} \cdot \mathrm{H}_{2} \mathrm{O}$ intercalate: A combined NMR, synchrotron XRD, and DFT calculations study. Chem. Mater. 20, 3944-3953 (2008)

Menéndez, A., Bárcena, M., Jaimez, E., García, J.R., Rodríguez, J.: Intercalation of $n$ alkylamines by $\gamma$-titanium phosphate. Synthesis of new materials by thermal treatment of the intercalation compounds. Chem. Mater. 5, 1078-1084 (1993)

Menéndez, F., Espina, A., Trobajo, C., Rodríguez, J.: Intercalation of $n$-alkylamines by lamellar materials of the $\alpha$-zirconium phosphate type. Mater. Res. Bull. 25, 1531-1539 (1990)

Ninjbadgar, T., Garnweitner, G., Borger, A., Goldenberg, L.M., Sakhno, O.V., Stumpe, J.: Synthesis of luminescent $\mathrm{ZrO}_{2}: \mathrm{Eu}^{3+}$ nanoparticles and their holographic sub-micrometer patterning in polymer composites. Adv. Funct. Mater. 9, 1819-1825 (2009)

O'Neill, A., Khan, U., Coleman, J.N.: Preparation of high concentration dispersions of exfoliated $\mathrm{MoS}_{2}$ with increased flake size. Chem. Mater. 24, 2414-2421 (2012)

Ortiz-Oliveros, H.B., Flores-Espinosa, R.M., Ordóñez-Regil, E., Fernández-Valverde, S.M.: Synthesis of $\alpha-\mathrm{Ti}\left(\mathrm{HPO}_{4}\right)_{2} \cdot \mathrm{H}_{2} \mathrm{O}$ and sorption of $\mathrm{Eu}(\mathrm{III})$. Chem. Eng. J. 236, 398-405 (2014)

Osada, M., Sasaki, T.: Two-dimensional dielectric nanosheets: Novel nanoelectronics from nanocrystal building blocks. Adv. Mater. 24, 210-228 (2012)

Oshima, T., Lu, D.L., Ishitani, O., Maeda, K.: Intercalation of highly dispersed metal nanoclusters into a layered metal oxide for photocatalytic overall water splitting. Angew. Chem. Int. Ed. 54, 2698-2702 (2015)

Parvez, K., Wu, Z.S., Li, R., Liu, X., Graf, R., Feng, X., Mullen, K.: Exfoliation of graphite into graphene in aqueous solutions of inorganic salts. J. Am. Chem. Soc. 136, 6083-6091 (2014)

Salvadó, M.A., Pertierra, P., García-Granda, S., García, J.R., Rodríguez, J., Fernandez-Diaz, M.T.: Neutron powder diffraction study of $\alpha$-Ti (HPO4) 2. H2O and $\alpha$-Hf (HPO4) 2. H2O: H-atom positions. Acta Cryst. B. 52, 896-898 (1996)

Shi, P., Xia, Z., Molokeev, M.S., Atuchin, V.V.: Crystal chemistry and luminescence properties of red-emitting $\mathrm{CsGd}_{1-\mathrm{x}} \mathrm{Eu}_{\mathrm{x}}\left(\mathrm{MoO}_{4}\right)_{2}$ solid-solution phosphors. Dalton Trans. 43, 9669-9676 (2014)

Sun, L.Y., Boo, W.J., Sun, D.Z., Clearfield, A., Sue, H.J.: Preparation of exfoliated epoxy/ $\alpha-$ zirconium phosphate nanocomposites containing high aspect ratio nanoplatelets. Chem. Mater. 19, 1749-1754 (2007)

Takei, T., Kobayashi, Y., Hata, H., Yonesaki, Y., Kumada, N., Kinomura, N., Mallouk, T.E.: Anodic electrodeposition of highly oriented zirconium phosphate and polyanilineintercalated zirconium phosphate films. J. Am. Chem. Soc. 128, 16634-16640 (2006)

Tanaka, H., Ishida, K., Okumiya, T., Murakami, M.: Preparation and exfoliation of layered titanium butyl phosphates. Colloid Polym. Sci. 288, 1427-1433 (2010)

Troup, J.M., Clearfield, A.: Mechanism of ion-exchange in zirconium phosphates. 20. Refinement of crystal structure of $\alpha$-zirconium phosphate. Inorg. Chem. 16, 3311-3314 (1977)

Wang, L.Z., Ebina, Y., Takada, K., Kurashima, K., Sasaki, T.: A new mesoporous manganese oxide pillared with double layers of alumina. Adv. Mater. 16, 1412-1416 (2004)

Wassei, J.K., Kaner, R.B.: Oh, the places you'll go with graphene. Acc. Chem. Res. 46, 2244$2253(2013)$

Xia, Z.Y., Pezzini, S., Treossi, E., Giambastiani, G., Corticelli, F., Morandi, V., Zanelli, A., Bellani, V., Palermo, V.: The exfoliation of graphene in liquids by electrochemical, chemical, and sonication-assisted techniques: A nanoscale study. Adv. Funct. Mater. 23, 4684-4693 (2013) 
Table 1. Fitting parameters of the biexponential temporal dependence for the luminescence decay curves of Eu_1.6 and Eu_2.4 monitored at 697 nm and excited at 394 nm.

\begin{tabular}{|c|c|c|c|}
\hline \multirow[b]{2}{*}{ Sample } & \multicolumn{2}{|c|}{$\tau(\mathbf{m s})$} & \multirow[t]{2}{*}{$j i^{\wedge 2}$} \\
\hline & $\tau_{1}$ & $\tau_{2}$ & \\
\hline Eu_1.6 & 0.16 & 0.51 & 1.295 \\
\hline $\mathrm{Eu}_{-}{ }^{-} \mathbf{2 . 4}$ & 0.26 & 0.65 & 1.262 \\
\hline
\end{tabular}




\section{Figure captions}

Figure 1. Powder XRD patterns for $\mathbf{E} \mathbf{u} \_\boldsymbol{x}$ samples.

Figure 2. $\mathrm{N}_{2} / 77 \mathrm{~K}$ adsorption-desorption isotherms of $\alpha$-TiP (a), $\alpha$-TiPPr (b), Eu_0.8 (c), Eu_1.6 (d) and Eu_2.4 (e) (Color figure on line).

Figure 3. SEM images of Eu_0 (a), Eu_0.8 (b), Eu_1.6 (c) and Eu_2.4 (d).

Figure 4. TEM images of Eu_o (a-c), Eu_0.8 (d-f), Eu_1.6 (g-i) and Eu_2.4 (j-1).

Figure 5. STEM-EDS elemental mapping for Eu_0 (a-f), Eu_0.8 (g-l), Eu_1.6 (m-r) and Eu_2.4 (s-x) samples; Ti (red), P (yellow), O (blue), C (cyan) and Eu (green) elemental maps.

Figure 6. AFM images of Eu_0 and their thickness profiles (Colour figure online).

Figure 7. Emission spectra of Eu_0 (violet), Eu_0.8 (green), Eu_1.6 (blue) and Eu_2.4 (red) samples obtained upon excitation at $394 \mathrm{~nm}$ (Colour figure online). 


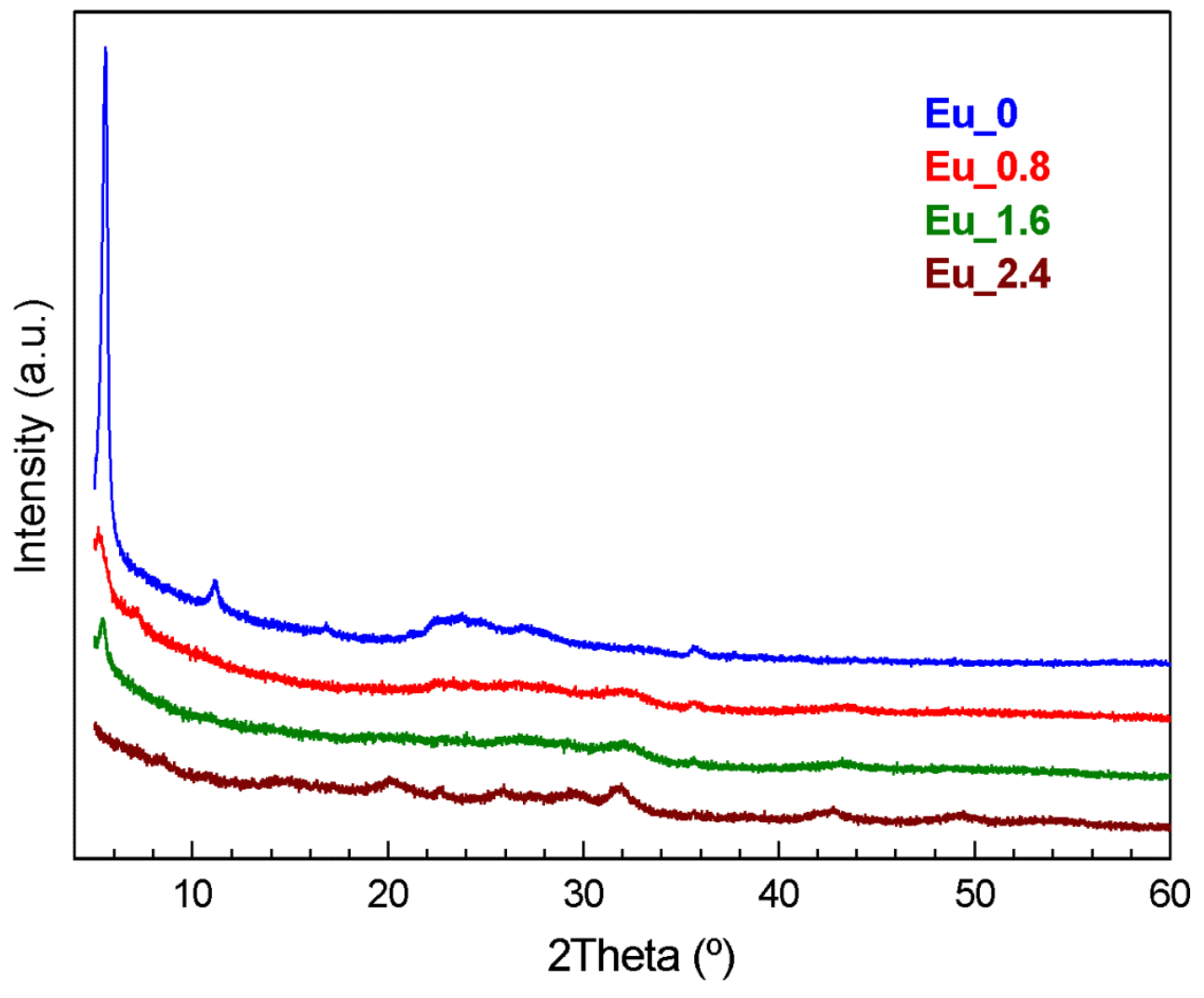

Figure 1 

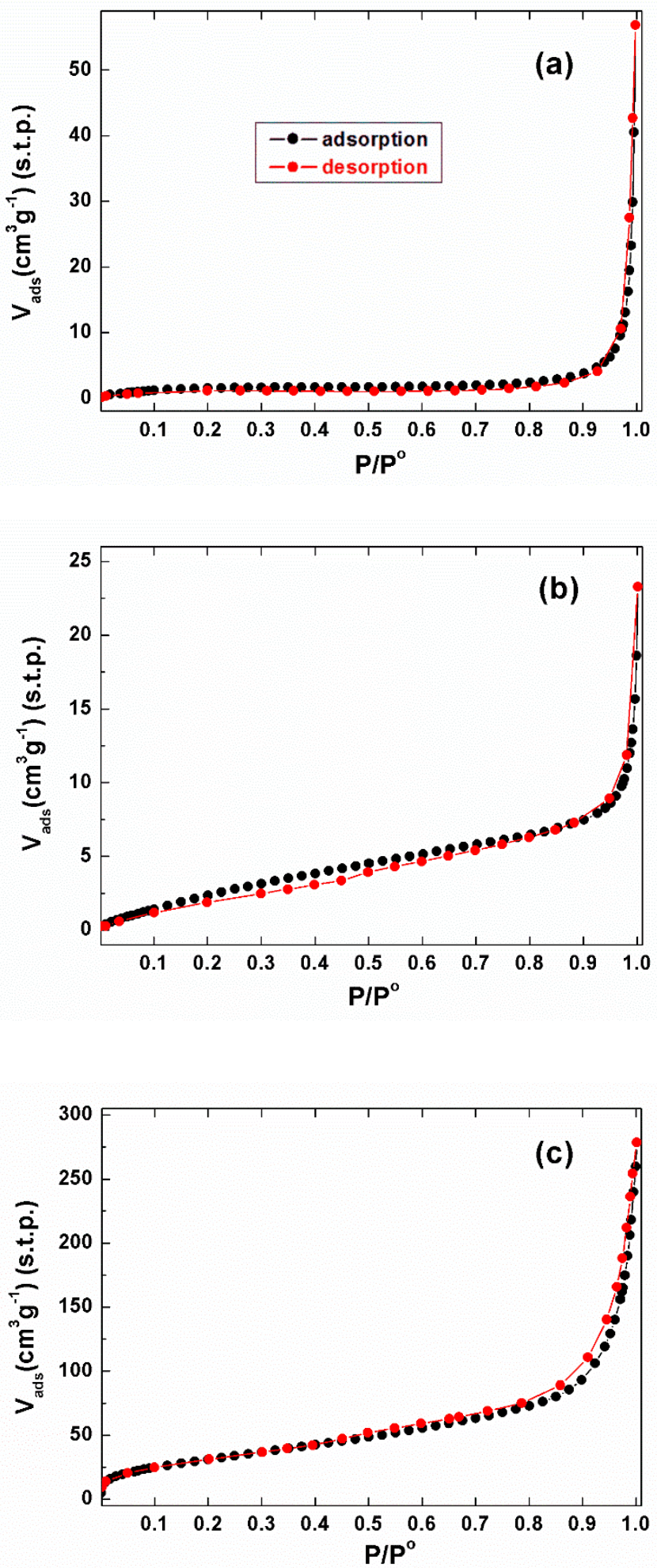

Figure 2 


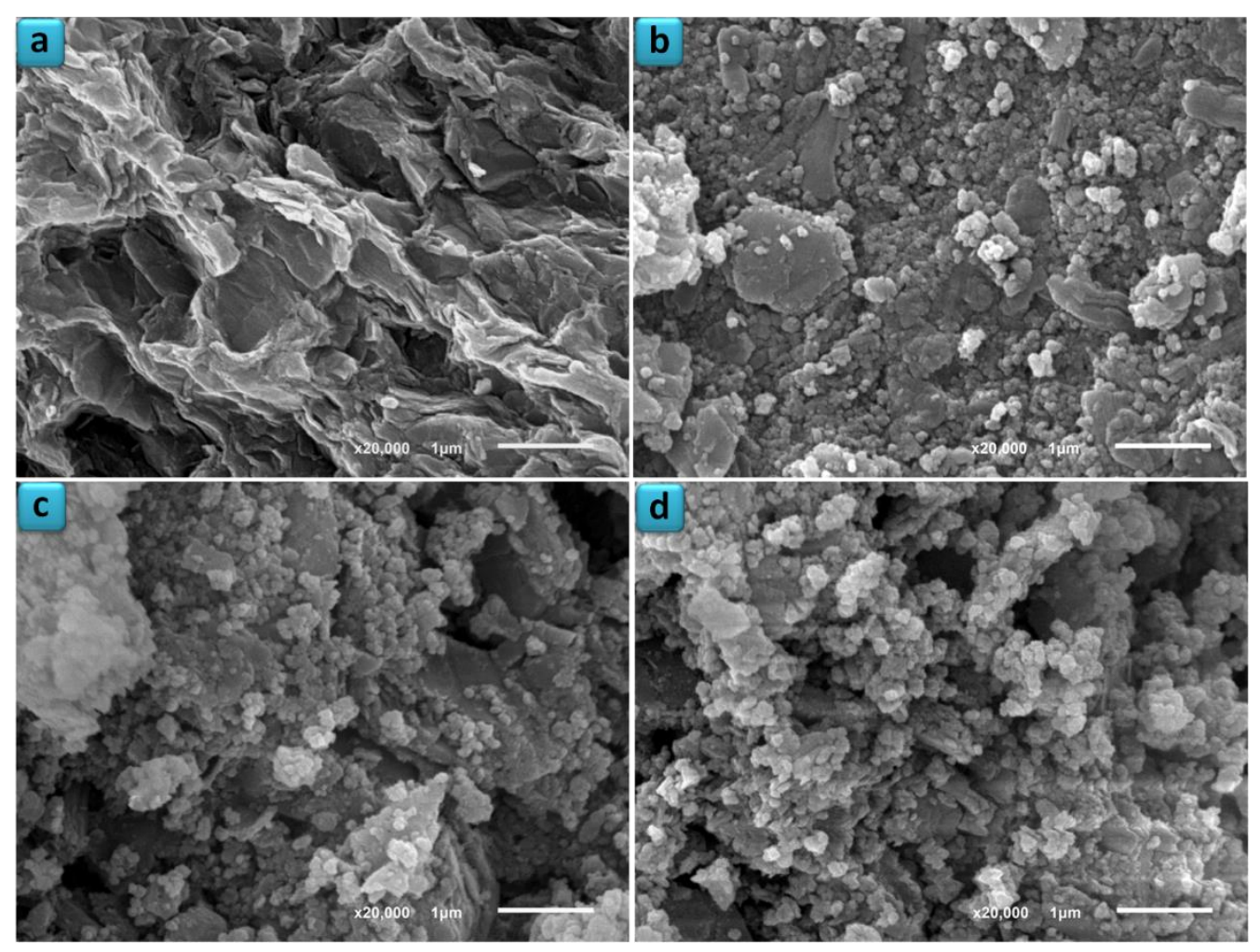

Figure 3 

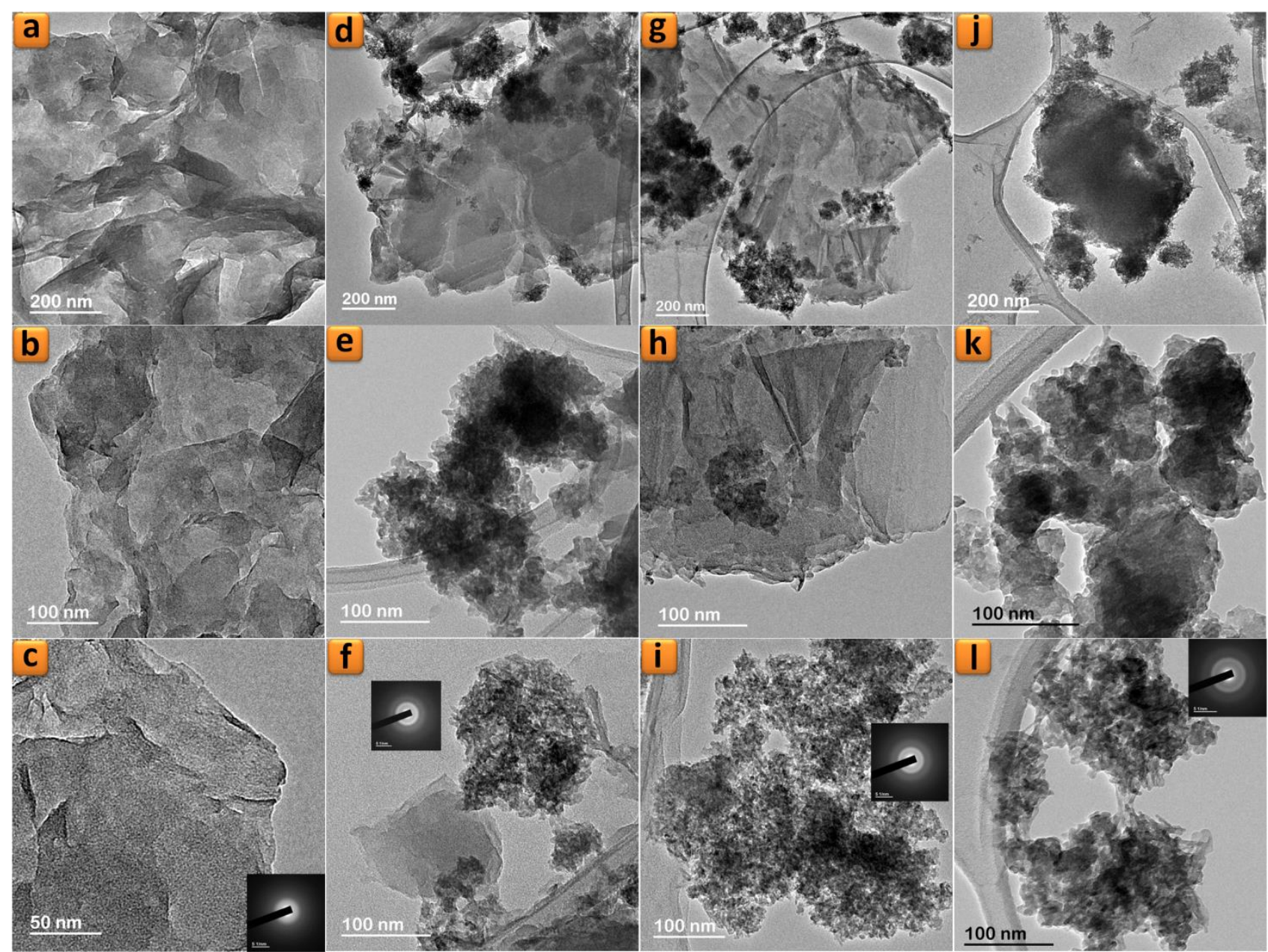

Figure 4 


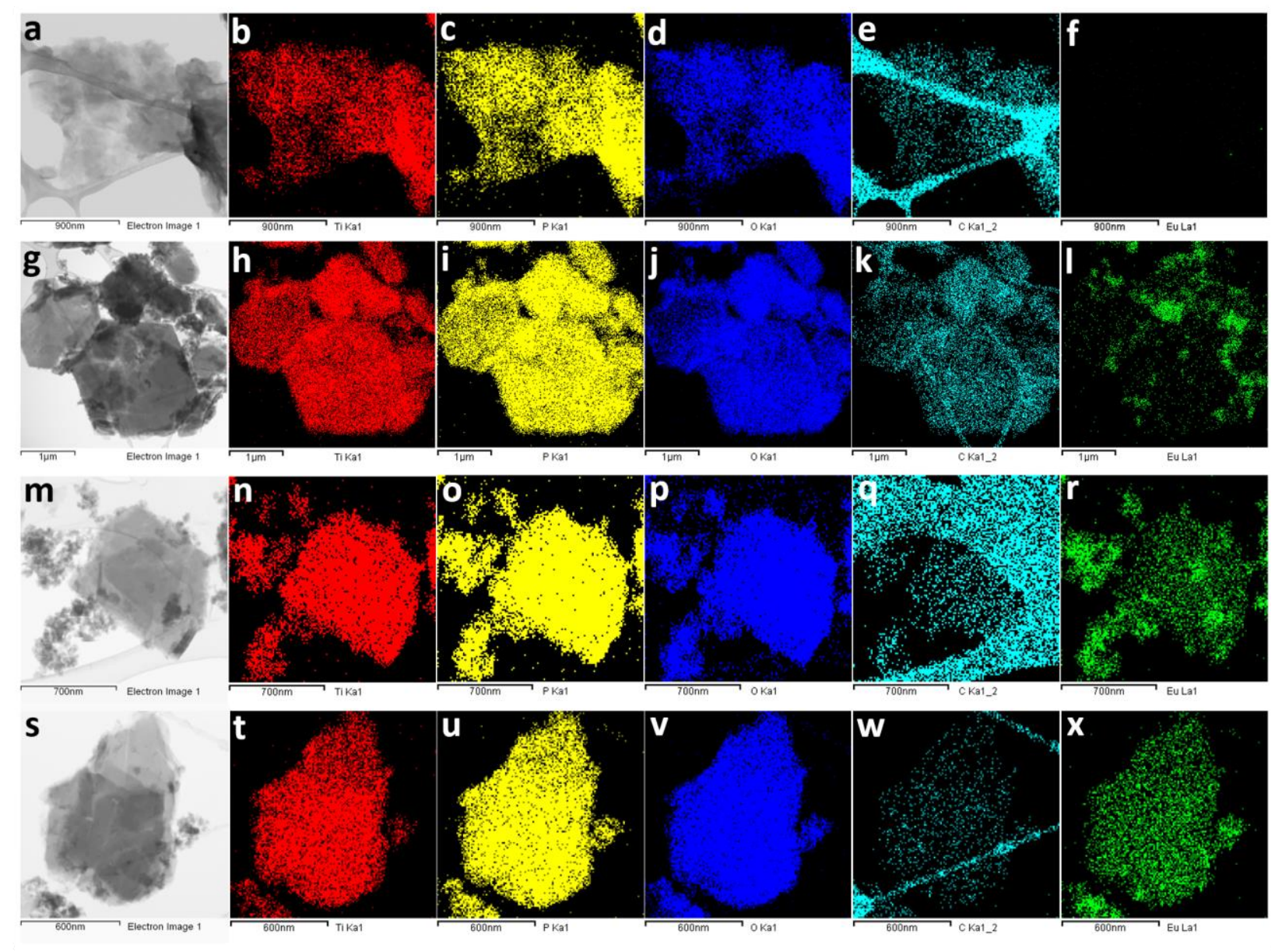

Figure 5 


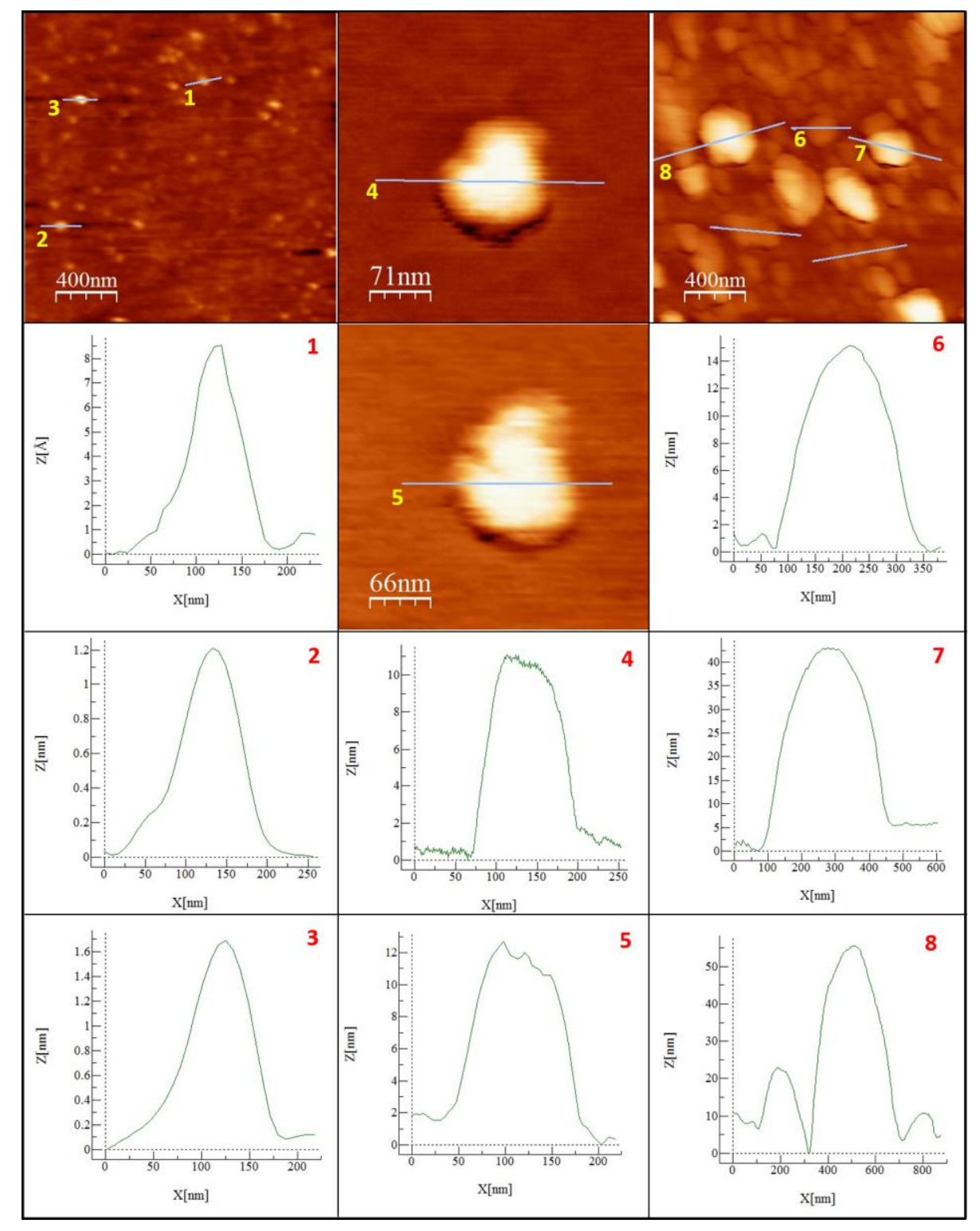

Figure 6 


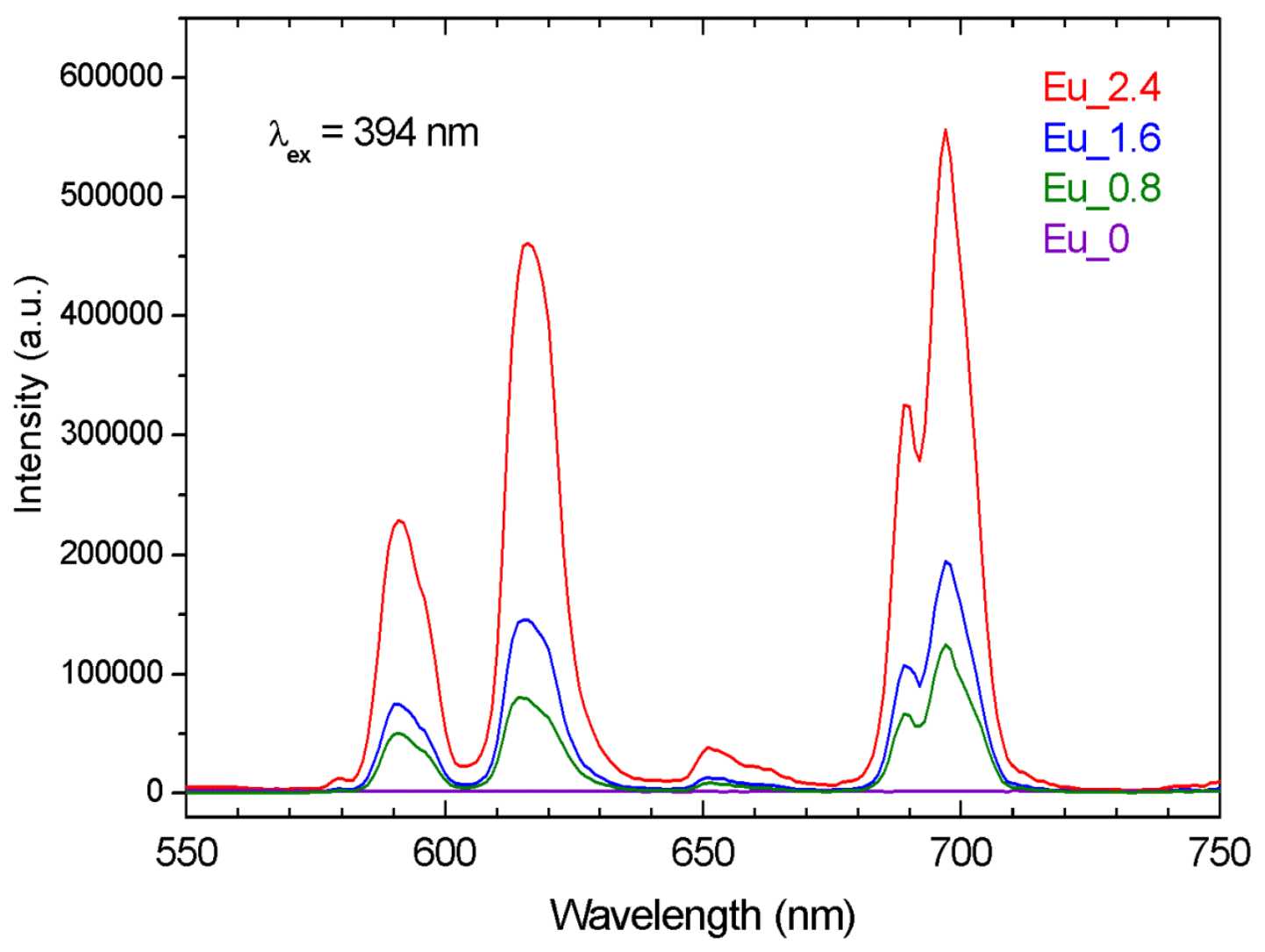

Figure 7 